\title{
Queimadas de cana-de-açúcar: avaliação de efeitos na qualidade do ar e na saúde respiratória de crianças
}

\author{
Helena Ribeiro e CÉlia PESQUERo
}

\section{Introdução}

A PRODUÇÃO DE cana-de-açúcar brasileira vem aumentando sobremaneira. A área plantada subiu de 5,6 milhões de hectares, na safra 2004/2005, para 5,9 milhões de hectares na safra 2005/2006. Há, também, a construção de mais de cem novas usinas de açúcar e álcool e ampliação do álcool na matriz energética. O Estado de São Paulo produz cerca de $60 \%$ da produção brasileira, em 3,4 milhões de hectares, em 2006, dos quais 2,5 milhões de hectares sofreram processo de queima da cana na pré-colheita, e em 900 mil hectares foi usada colheita mecanizada. Da produção brasileira, só $25 \%$ têm colheita mecanizada e o restante é queimado antes da colheita manual.

No Estado de São Paulo, a queima da cana coincide com período de baixas precipitações e piores condições de dispersão, agravando seus efeitos na qualidade do ar.

Internamente, o álcool vem tendo maior demanda, sobretudo em razão do desenvolvimento dos motores flexíveis, que rodam com álcool ou gasolina. Quando abastecido com álcool, o automóvel consome cerca de 30\% a mais em relação à gasolina; portanto, só é vantajoso abastecer com álcool quando o seu preço é até $70 \%$ o preço da gasolina (Silva, 2006). Assim, o preço do álcool é fator de grande significância para o mercado consumidor. Segundo Weekes (2004), a colheita e o transporte representam aproximadamente $25 \%$ a $35 \%$ dos custos totais da produção, e, por isso, há esforços para minimização desses gastos. A colheita e o transporte da cana queimada são mais baratos do que os custos relacionados à cana verde. Além disso, a produtividade de cortadores manuais em cana queimada chega a ser o dobro do verificado na cana verde. Portanto, eles também preferem cortar cana queimada, apesar de ficarem expostos a maiores níveis de poeira e fuligem, como pode ser visualizado nas fotos 1 e 2 .

Por sua vez, a colheita mecanizada da cana apresenta algumas restrições: alto investimento, elevada capacidade operacional e risco de tombamento das máquinas em topografia com declividade acima de $12 \%$.

Em 2002, foi aprovada, no Estado de São Paulo, a Lei n.11.241, que dispõe sobre a eliminação da queima da palha da cana-de-açúcar e estabelece um cronograma do ano 2002 a 2031, com porcentagens de áreas plantadas onde a queima 


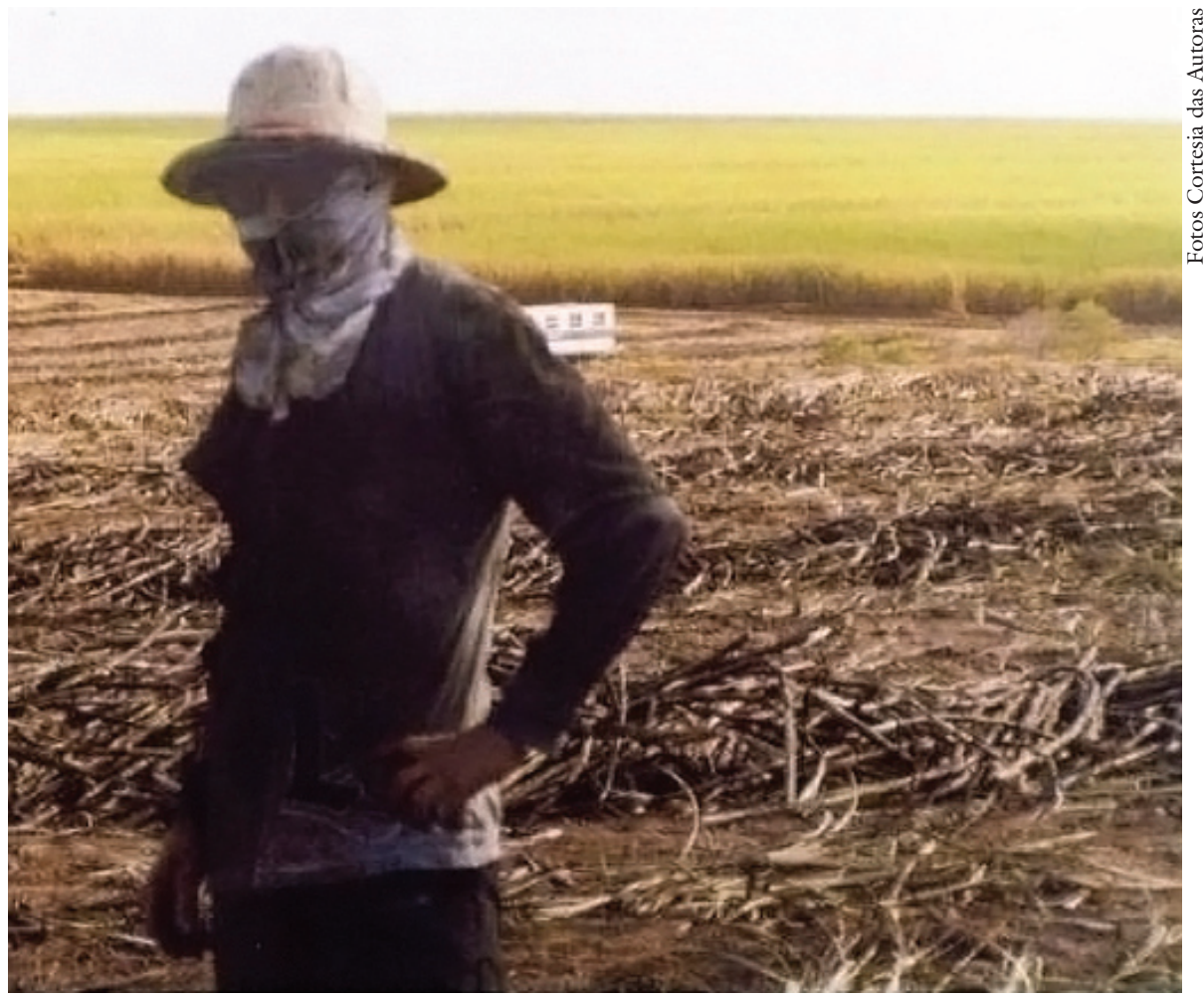

Cortadora de cana tenta se proteger da poeira, em Lençóis Paulista, 2005. (Foto 1)

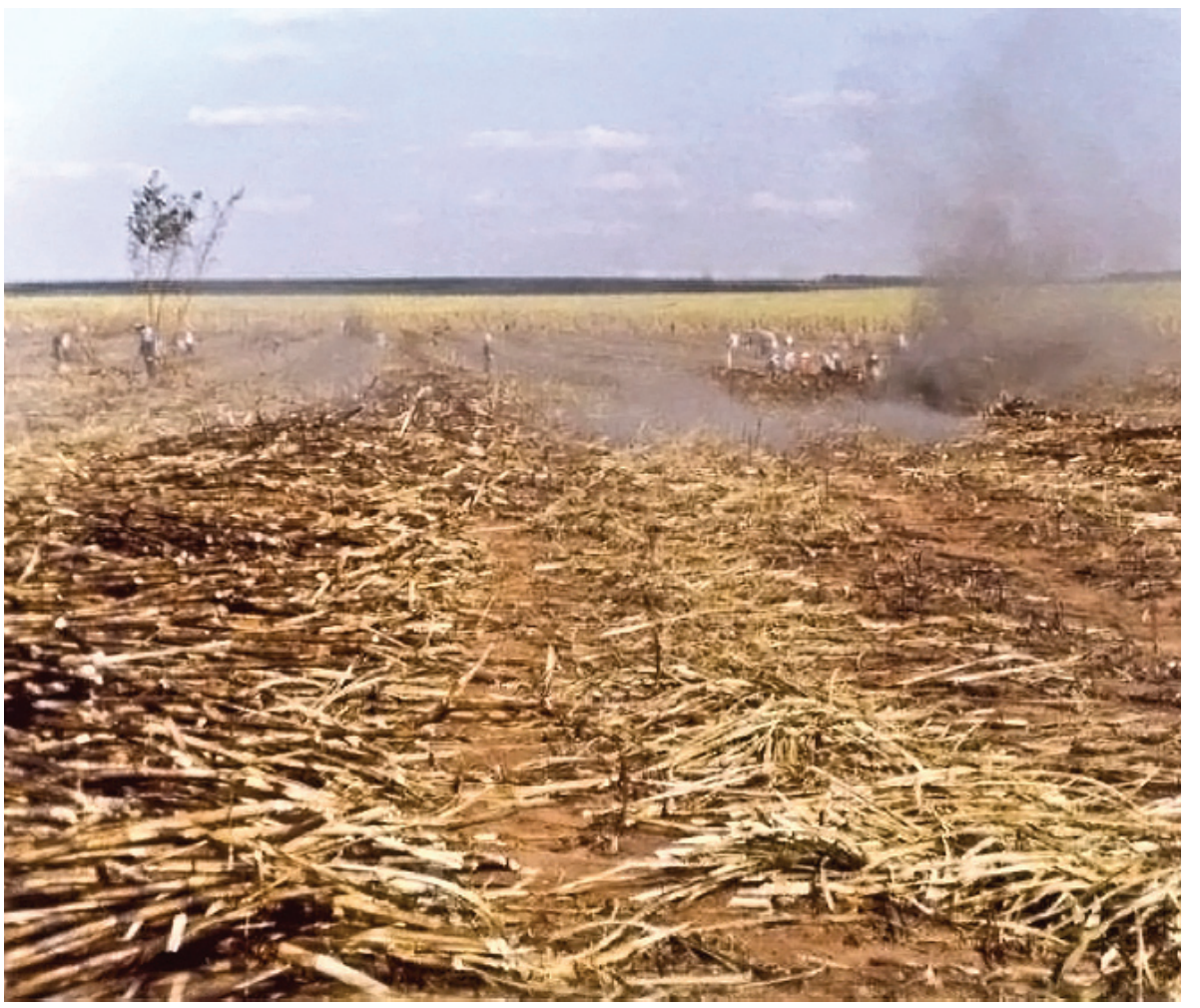

Fuligem da cana e poeira ressuspensas pelo vento, em Lençóis Paulista, 2005. (Foto 2) 
deve ser eliminada, que vão de $20 \%$ no primeiro ano a $100 \%$ em 2021 , para áreas mecanizáveis, e até 2031 para áreas não mecanizáveis. Além disso, a lei pró́be queimada a um quilômetro do perímetro de áreas urbanas e de reservas indígenas, e exige dos plantadores um planejamento anual a ser entregue à Companhia de Saneamento Ambiental do Estado de São Paulo (Cetesb), adequando as áreas de produção ao plano de eliminação das queimadas.

Em 2007, o governo do Estado e a União da Indústria de Cana-de-Açúcar (Unica) assinaram protocolo de intenções fixando novas metas para adoção da mecanização, no qual, nas áreas passíveis de mecanização, a queimada deverá ser abandonada em 2014 e nas de declividade maior que 12\% até 2017 (O Estado de $S$. Paulo, 2007). Já para fornecedores de cana, a proposta é que a eliminação total ocorra até 2021.

Os canaviais, entretanto, constituem importante fonte de empregos para uma fração da população com baixo nível de instrução, representando a maior demanda de força de trabalho agrícola no Estado de São Paulo, com o equivalente de 250.907 homens-ano, em 2002, equivalentes a $35 \%$ de toda força de trabalho agrícola (Braunbeck \& Magalhães, 2004).

A proibição da queima de cana-de-açúcar para seu despalhamento pré-colheita representa um dilema socioambiental. Ao mesmo tempo que a sua proibição pode contribuir para melhoria da qualidade do ar e, portanto, para a sustentabilidade ambiental e a prevenção de doenças, ela pode suprimir milhares de empregos no campo, gerando insustentabilidade social e espacial.

Alguns poucos estudos foram realizados no Brasil e no exterior para avaliar efeitos da queimada de cana-de-açúcar na saúde da população que vive em seus arredores. A grande maioria deles preocupou-se em avaliar efeitos agudos de episódios de queima à saúde da população, em curto prazo. Destacam-se, no Brasil, as pesquisas de Arbex et al. (2000), Cançado (2003) e Lopes \& Ribeiro (2006), que indicaram que, em períodos de queima de cana, há maior quantidade de visitas hospitalares, inalações e internações hospitalares por doenças respiratórias em cidades próximas. Nos Estados Unidos, pesquisa de Boopathy et al. (2002) também indicou aumento de tendência de hospitalizações por asma nos meses de queima de palha de cana, no Estado de Louisiana, onde a prática existe. Bebês foram os mais afetados.

O objetivo principal do presente estudo foi avaliar impacto da queima de cana-de-açúcar na qualidade do ar em área sujeita anualmente a esse processo e os efeitos da poluição crônica, em longo prazo, nas condições de saúde respiratória de escolares vivendo na região, almejando contribuir para a discussão de soluções desse dilema, ampliando a base de dados e informações disponíveis para tomada de decisão.

\section{Métodos e técnicas}

\section{Seleção da área de pesquisa}

A seleção da área foi feita após visita a diversos municípios do Estado de São 
Paulo com grande parte de suas terras utilizadas para produção de cana-de-açúcar. Esses municípios, no entanto, apresentavam fatores de confusão, como industrialização e tráfego intenso de veículos. Selecionou-se então um município de base econômica rural, cuja população dependesse especialmente das atividades voltadas à cultura da cana-de-açúcar e com baixo volume de tráfego de veículos: Espírito Santo do Turvo, situado no oeste paulista, a 320 quilômetros da capital, no km 315 da Rodovia Castelo Branco, no sentido São Paulo-Bauru, delimitando-se com os municípios de Santa Cruz do Rio Pardo e Agudos.

Espírito Santo do Turvo possui área de $194 \mathrm{~km}^{2}$, ou 19.415 hectares. Em 1978, aí foi instalada uma destilaria de álcool. A economia rural do município baseia-se na criação de gado e na monocultura canavieira, que ocupa de $8 \%$ a $22 \%$ de sua área total, conforme observado na Tabela $\mathrm{l}$, pois a área classificada como solo descoberto está em grande parte sendo preparada para plantio de cana. A economia urbana baseia-se em atividades comerciais e de serviços, organizadas para atender às demandas locais (Donzelli et al., 2006).

Tabela 1 - Uso atual das terras de Espírito Santo do Turvo

\begin{tabular}{l|r|r}
\hline Uso atual & Área (ha) & $\%$ \\
\hline Solo descoberto & 2720,88 & 14,01 \\
\hline Cana-de-açúcar & 1628,01 & 8,38 \\
\hline Fruticultura & 9,45 & 0,05 \\
\hline Seringueira & 18,54 & 0,10 \\
\hline Cobertura residual & 96,03 & 0,49 \\
\hline Pastagem & 13213,26 & 68,03 \\
\hline Reflorestamento & 265,32 & 1,37 \\
\hline Mata/ mata ciliar/ capoeira & 983,43 & 5,06 \\
\hline Várzea & 487,98 & 2,51 \\
\hline Total & 19422,9 & 100,00 \\
\hline
\end{tabular}

Fonte: Donzelli et al. (2006).

A análise da topografia e da carta de declividades permitiu verificar que há grande potencial de expansão de plantações de cana no município e na região, pois as terras com declividades inferiores a $12 \%$ perfazem $91 \%$ da área agrícola municipal, conforme observado na Tabela 2. Portanto, não há restrições de ordem topográfica à mecanização da colheita. Por sua vez, a usina de processamento de cana aí instalada tem potencial para ampliar sua produção e planeja fazê-lo gradualente.

Quanto aos aspectos físico-naturais, o município apresenta solos suscetíveis a erosão, com presença de argissolos textura arenosa/média com caráter abrúptico, bastante problemáticos para atividades agrícolas, não tanto pelo fato de refletir 
baixas produtividades, mas pela elevada suscetibilidade a erosão. Sem cobertura vegetal protetora, são facilmente erodidos, causando assoreamento dos mananciais hídricos (Bertolani et al., 2006). A cobertura vegetal nativa remanescente ocupa apenas $7,57 \%$ de sua área, sendo 5,06\% de matas mesófilas semidecíduas e ciliares e 2,51\% de várzeas e trechos estreitos de matas ciliares em recuperação. Os fragmentos de vegetação nativa são pequenos, os maiores não chegam a atingir 200 ha de área. Os cerrados, apontados como existentes anteriormente no município em estudos desenvolvidos pelo Instituto Florestal, não foram encontrados em trabalho de campo feito em 2000. Foram observadas apenas algumas espécies típicas de cerrado, com indivíduos isolados, mas não o ecossistema (Torres, 2006).

Tabela 2 - Classes de declividade no município de Espírito Santo do Turvo

\begin{tabular}{l|c|c}
\hline Classes de declive & Área (ha) & $\%$ \\
\hline A: $0-3 \%$ & 6148,62 & 31,79 \\
\hline B: $3 \%-6 \%$ & 5845,05 & 30,22 \\
\hline C: $6 \%-12 \%$ & 5690,97 & 29,42 \\
\hline D: $12 \%-20 \%$ & 1386,27 & 7,17 \\
\hline E: $20 \%-40 \%$ & 260,01 & 1,34 \\
\hline F: $>40 \%$ & 12,96 & 0,07 \\
\hline Total & 19343,88 & 100,00 \\
\hline
\end{tabular}

Fonte: Donzelli et al. (2006).

A Usina Agrest - Agroindustrial Espírito Santo do Turvo, aí instalada, colhe uma área de 4 mil ha em cana-de-açúcar, em Espírito Santo do Turvo e arredores, e está procurando novas áreas para fornecimento nas proximidades. $\mathrm{O}$ ideal, segundo seu presidente, seria receber de um raio de 20 quilômetros, para garantir que a cana não fermente antes do processamento e para diminuir os custos de transporte. Em 2004, a usina processou cerca de $5 \mathrm{mil} \mathrm{t} /$ dia de cana, mas possui capacidade para processar até $11 \mathrm{mil} \mathrm{t} /$ dia. Naquele mesmo ano, empregava três mil funcionários diretos em todos os níveis, incluindo os cortadores. A colhedeira mecânica não havia sido introduzida aí e a queimada era praticada durante toda a safra. Nos plantios novos, já vinham preparando o terreno para introdução da colheita mecanizada. Além disso, a indústria ainda não havia instalado lavadores de gases (conforme comunicação pessoal do diretor-presidente).

Na Foto 3, pode-se observar a Usina Agrest de uma rua da área urbana de Espírito Santo do Turvo, ilustrando essa proximidade.

De acordo com o Censo Demográfico, em 2000, Espírito Santo do Turvo possuía 3.677 habitantes, sendo 51,5\% homens e 48,5\% mulheres. Do total, 3.239 pessoas moravam na área urbana $(88,9 \%)$ e $438(11,1 \%)$ na zona rural. A densidade demográfica do município era de 19,2 habitantes por $\mathrm{km}^{2}$, bastante inferior ao índice verificado para o Estado, de $139 \mathrm{hab} . / \mathrm{km}^{2}$. A taxa de mortalidade geral 


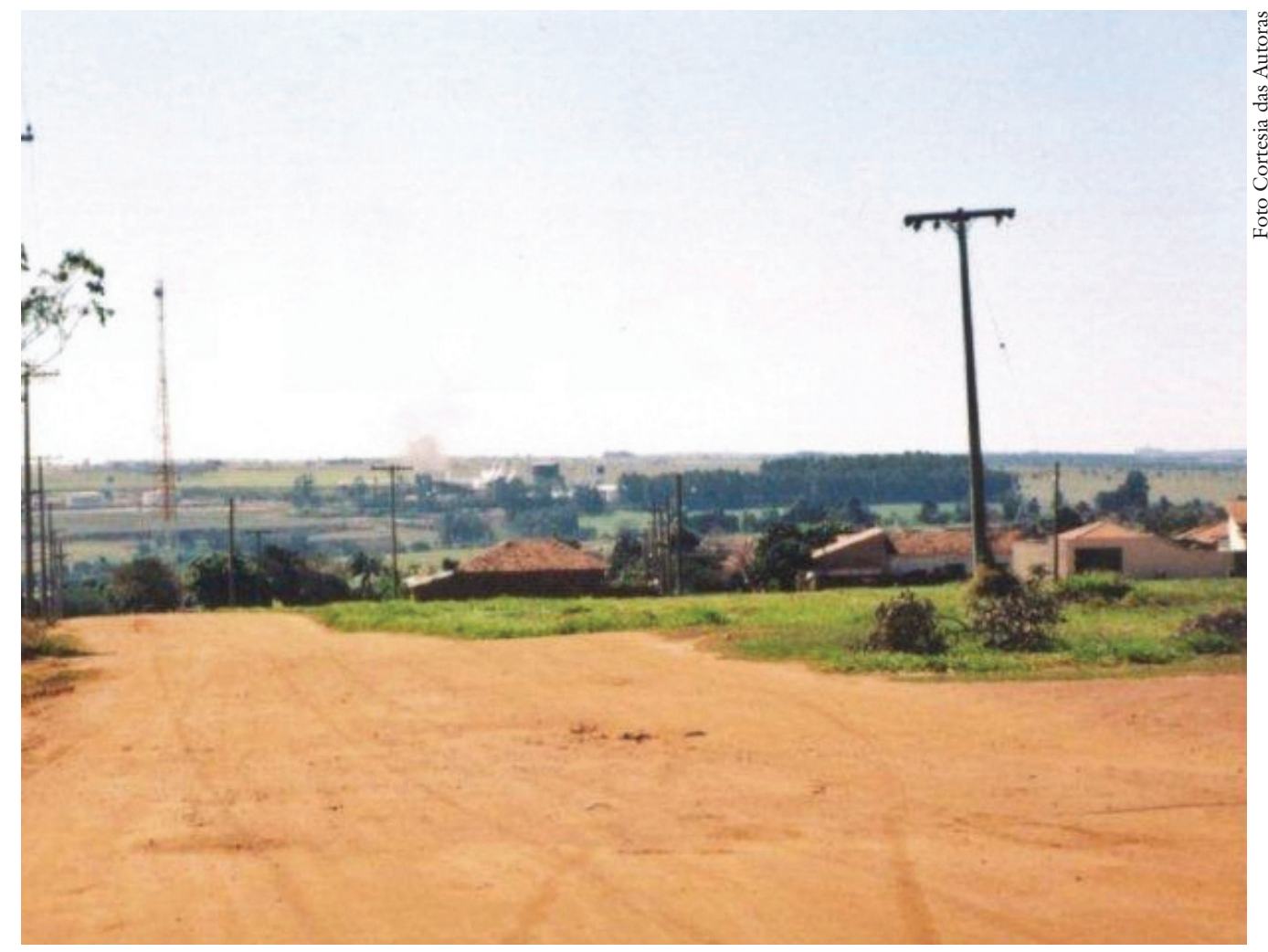

Usina Agrest vista da área urbana de Espirito Santo do Turvo, 2005. (Foto 3)

era de 7,63/1.000, pouco superior ao índice do Estado. A mortalidade infantil $(15,15 / 1.000)$ foi inferior à taxa do Estado em 2000. Dados de escolaridade do município indicaram $21,7 \%$ de habitantes não alfabetizados, $63,7 \%$ com 1 a 7 anos de escolaridade, e só $0,7 \%$ da população com mais de 15 anos de estudo (IBGE, 2000).

Em levantamento realizado junto aos moradores do município sobre seus problemas ambientais e possíveis efeitos à saúde, foram indicados: poluição do rio, desemprego, lixo, fumaça de queimada de cana-de-açúcar, erosão de solo e mosquitos. Muitos entrevistados consideraram que as queimadas causavam impactos à comunidade, motivando doenças respiratórias e sujando as ruas e casas por causa da poeira (Ribeiro \& Günther, 2006).

Considerou-se assim o município adequado para a pesquisa. O conhecimento prévio da área e a aceitação da escola municipal para a instalação dos medidores de poluição do ar e da escola estadual para a aplicação dos questionários aos alunos foram fatores que facilitaram a realização de parte de campo da pesquisa.

\section{Aplicação de questionários}

Foi realizada aplicação de 144 questionários sobre morbidade respiratória referida em estudantes da Escola Estadual Terezinha Mariano Magnani de Espírito Santo do Turvo. Crianças de 10 a 13 anos de idade foram escolhidas como grupo objeto de estudo porque elas são mais suscetíveis à poluição do ar, não fumam 
e não foram afetadas por poluição de origem ocupacional. Responderam alunos de $5^{\underline{a}}(53,6 \%)$ e $6^{\underline{a}}(46,45 \%)$ séries. O instrumento de pesquisa utilizado foi um questionário desenvolvido para avaliação de efeitos de poluição do ar em longo prazo, pelo Epidemiology Standardization Project (Ferris, 1978) da Pulmonary Disease Division do National Heart, Lung and Blood Institute, dos Estados Unidos, para crianças com até 13 anos de idade. O questionário levanta aspectos socioeconômicos, sintomas de doenças respiratórias dos últimos dois anos anteriores à pesquisa e doenças respiratórias de todo período de vida das crianças. Não é um instrumento de pesquisa para levantar efeitos agudos da poluição do ar, por isso sua aplicação não necessita ser coincidente com os dias em que é feita a medição de poluentes atmosféricos e de ventos. O monitoramento dos poluentes foi feito em duas campanhas de alguns dias, em dois anos seguidos, durante a safra de cana, para conhecer os níveis a que a população vem sendo exposta.

Como só existe uma escola pública com alunos na faixa etária desejada no município e não há indicações de discrepâncias significativas de renda entre as famílias que aí moram, considerou-se que as diferenças sociais foram controladas. Os questionários foram aplicados na escola, no mês de setembro, para evitar as temperaturas mais frias de inverno, durante período de aulas, por esta pesquisadora, em conjunto com alguns alunos de pós-graduação da Faculdade de Saúde Pública, e o índice de resposta foi de $100 \%$. Só um questionário foi descartado. Todas as crianças naquela faixa etária da escola foram incluídas na pesquisa para atender ao critério de definição do tamanho da amostra, adotando um erro padrão de $5 \%$, usando a seguinte fórmula:

$$
n=\frac{n o}{1+\frac{n o-1^{\prime}}{N}}
$$

Onde

$$
n o=\frac{P \times Q}{\sigma^{2} \rho}
$$

no é o número estimado da amostra; $n$, o tamanho da amostra ajustado para o fator de população finita; $N$, o tamanho total da população; $P$, a taxa de prevalência de uma doença expressa como porcentagem de uma população total; $Q$ o complemento $(\mathrm{Q}=1-\mathrm{P}) ; \sigma^{2} \rho$, o desvio padrão da prevalência $\mathrm{P} ; \sigma^{2} \rho$ adotado foi $5 \%$, considerado adequado para estudos epidemiológicos e dentro das limitações financeiras e de pessoal do projeto.

Posteriormente, os resultados foram comparados com aqueles obtidos em pesquisa anterior realizada pela autora no município de Juquitiba, localizado em área de proteção aos mananciais na Região Metropolitana de São Paulo, sem a presença de queimada de cana e de outras atividades poluidoras do ar. O instru- 
mento de pesquisa e sua forma de aplicação foram os mesmos utilizados em Espírito Santo do Turvo (Ribeiro \& Cardoso, 2003).

\section{Medições da qualidade do ar}

As medições de qualidade do ar foram realizadas em duas campanhas de monitoramento, durante período de safra de cana-de-açúcar, em área urbana do município de Espírito Santo do Turvo, uma vez que havia interesse em verificar os níveis de poluentes a que a população escolar estava sujeita. Como informado, a usina de produção localiza-se bem próxima à área urbana, e as áreas de plantação de cana quase que circundam a cidade.

Antes do monitoramento, foram solicitadas à Cetesb as datas de comunicação de queima no município, para que coincidissem com as medições. Durante a campanha de 2004, a estação seca e a safra já estavam no final e choveu em dois dias, o que pode ter restringido a ocorrência de queimadas. Em 2005, a campanha ocorreu em plena estação seca e no meio da safra, para se ter dados de um período mais crítico de poluição. Houve, ainda, observação de fortes ventos em alguns períodos, apesar de esses não terem sido medidos. Como não há estação meteorológica no município, foram solicitados de Bauru, a estação mais próxima, dados sobre predominância e intensidade média de ventos em diferentes horas do dia. Foram fornecidos dados das médias de 1999 a 2001, com elaboração das rosas de ventos para os diferentes períodos do dia, para conhecer o padrão médio de direção predominante de ventos na região e avaliar se poderiam influir nos resultados.

Foram feitas medições de Material Particulado Total em Suspensão (PTS), Material Particulado Inalável (PM10) e Dióxido de Nitrogênio $\left(\mathrm{NO}_{2}\right)$, pelo Laboratório de Qualidade do Ar da Faculdade de Saúde Pública da USP. Os amostradores ficaram localizados na Escola Municipal do Campo, situada na zona urbana de Espírito Santo do Turvo, nos períodos de 8 a 12 de novembro de 2004, e de 6 a 12 de julho de 2005.

O Material Particulado Total em Suspensão foi coletado usando um amostrador de grande volume Energética, de acordo com o método da Associação Brasileira de Normas Técnicas (ABNT: NBR 9547, 1993). As amostras foram coletadas em filtro de fibra de vidro (203 x $254 \mathrm{~mm})$, durante 24 horas, nos dias: 8, 9, 10, 11 e 12 de novembro de 2004, e 6, 7, 8, 9, 10, 11 e 12 de julho de 2005, com início e término de coleta em torno de 8 horas da manhã, a uma vazão entre 1,40 e $1,540 \mathrm{~m}^{3} / \mathrm{min}$. Antes da primeira coleta, o amostrador foi calibrado com calibrador de orifício e manômetro de coluna d'água em $\mathrm{U}$, segundo a recomendação do método. A massa de material particulado foi determinada gravimetricamente, por meio da pesagem dos filtros antes e após a amostragem, utilizando uma balança analítica Mettler Toledo AG-204 com precisão de 0,1 mg. Antes das pesagens, os filtros foram estabilizados por 24 horas em dessecador com sílica gel, para remoção da umidade. O depósito de material no filtro e a velocidade de fluxo apresentam nível de precisão de $\pm 2 \mathrm{mg}$ e $5 \%$, respectivamente. As precisões determinadas pela colocação dos equipamentos variam na faixa de 4\% a 10\% (Lodge Junior, 1988). 
Simultaneamente à coleta do Material Particulado em Suspensão (PTS), foram coletadas amostras de Material Particulado Inalável PM10, nos dias 6, 7, 8, 9, 10,11 e 12 de julho de 2005, usando um amostrador de grande volume Wedding, de acordo com o método (ABNT: NBR 13412, 1995). As amostras foram coletadas durante 24 horas a uma vazão de 1,148 a $1,166 \mathrm{~m}^{3} / \mathrm{min}$ em filtro de fibra de vidro $(203 \times 254 \mathrm{~mm})$. Antes e depois da coleta, o amostrador foi calibrado por meio de um manômetro de coluna d'água em $\mathrm{U}$, segundo recomendação do método. Os filtros foram pesados antes e depois da amostragem em balança analítica Mettler Toledo AG-204 com precisão de 0,1 mg. Antes da pesagem, os filtros foram estabilizados em dessecador com sílica gel por 24 horas, para remoção da umidade.

A concentração do dióxido de nitrogênio $\left(\mathrm{NO}_{2}\right)$ atmosférico foi determinada pelo método de Saltzman (WHO, 1976; Lodge Junior, 1988), utilizando um amostrador de gases Energética modelo Tri-gás. Foram feitas coletas nos dias 8, 9, 10, 11,12 de novembro de 2004, e 6, 7, 8, 9, 10, 11 e 12 de julho de 2005, no período da manhã, horário das 8 h30 às 9 h30, nos dias 7 a 13, e nos dias 6 a 12, no horário das $19 \mathrm{~h}$ às $20 \mathrm{~h}$. Foram utilizados dois borbulhadores com dispersor poroso, em série, contendo $15 \mathrm{~mL}$ de reagente absorvente (solução a $0,002 \%$ de di-hidrocloreto de n-(1-naftil) etilenodiamina, $0,026 \mathrm{M}$ de ácido sulfanílico e 2,45M de ácido acético). A vazão de amostragem utilizada foi de aproximadamente $0,550 \mathrm{~L} / \mathrm{min}$ e tempo de coleta de 60 minutos. Uma precisão média de $1 \%$ pode ser obtida com o método empregado (Lodge Junior, 1988). As amostras foram analisadas em espectrofotômetro Shimadzu modelo UV 1203, a 550 nm, utilizando curva de calibração construída com cinco concentrações de solução padrão de nitrito de sódio.

\section{Resultados e discussão \\ Qualidade do ar}

Verificou-se, pela rosa dos ventos da região (Figura 1), que durante a tarde há circulação de ar de todas as direções. A queima da cana é sempre realizada no final da tarde e início da noite, pois, com o resfriamento do ar ambiente, há maior facilidade de subida do ar quente e consequente dispersão da fumaça. Assim, não havendo um padrão definido de incidência de ventos predominantes, nem um local único de queima, supôs-se que, de maneira geral, a qualidade do ar urbano seja afetada pelas emissões produzidas pelas queimadas e que a sua população urbana esteja sujeita a seus efeitos.

As figuras 2 a 6 mostram os resultados das medições realizadas nas campanhas de amostragem de 2004 e 2005 e os padrões de qualidade do ar anual e para 24 horas por Particulado Total - PTS e para uma hora por dióxido de nitrogênio, estabelecidos pela Resolução Conama.

Verificou-se, pelos dados constantes das Figuras 2 a 6, nos períodos amostrados, que os níveis de poluentes medidos estiveram sempre abaixo dos padrões horários e anuais para dióxido de nitrogênio e diários e anuais para material particulado total e partículas inaláveis permitidos pela legislação brasileira. Como mencionado no item "Métodos e técnicas", as medições foram realizadas durante a safra de 


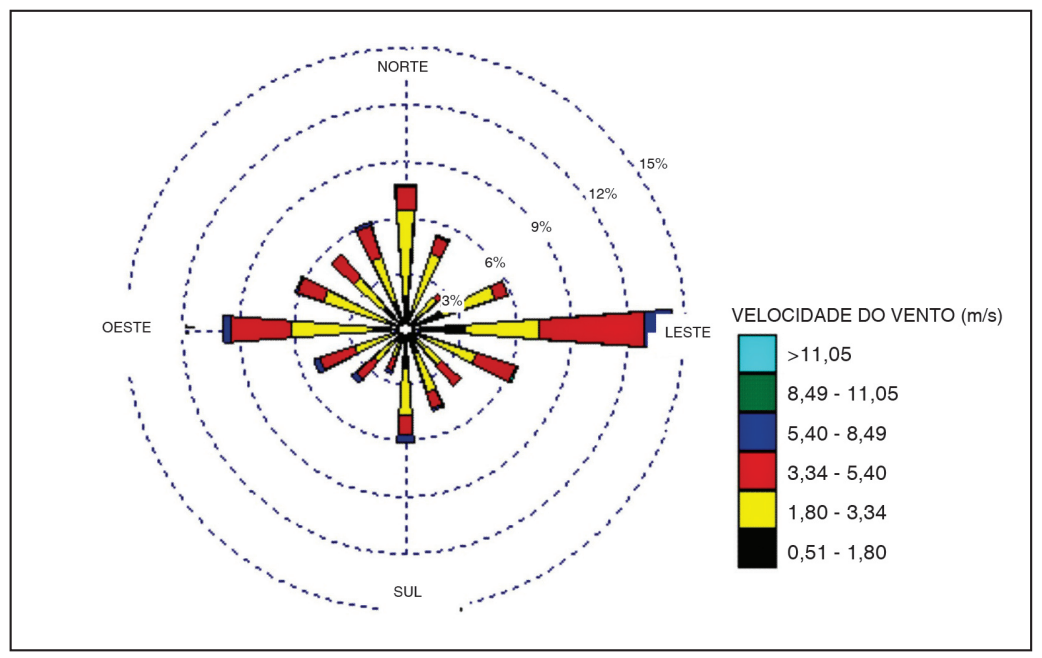

Figura 1 - Ventos Bauru 10/1999 a 12/2001 - Durante o período da tarde.
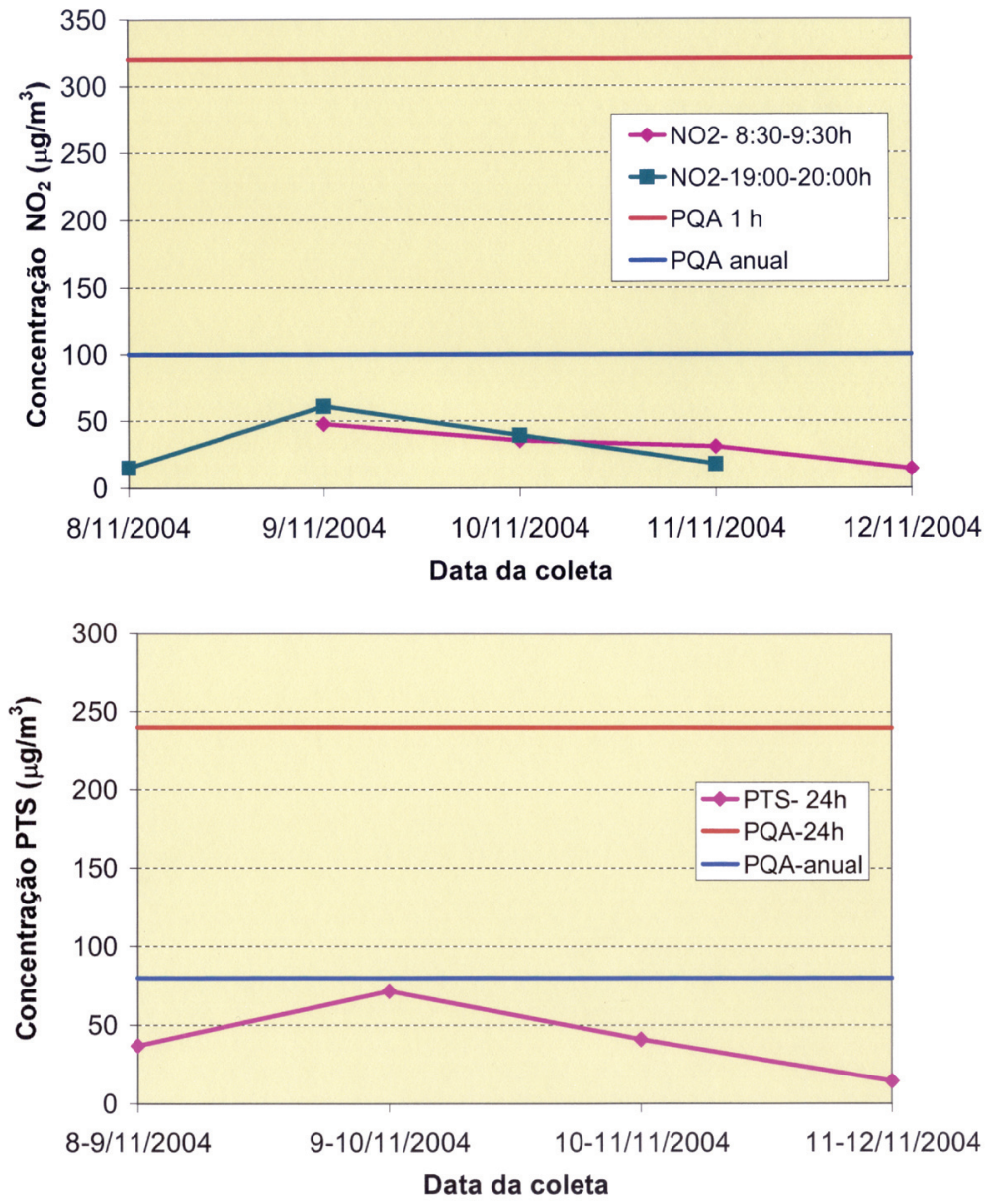

Figuras 2 e 3 - Concentrações de Particulado Total em Suspensão e de dióxido de nitrogênio no período de 8 a 12 de novembro de 2004, e padrões de qualidade do ar diário, para 1 hora e anual, em área urbana de Espírito Santo do Turvo. 
cana no município, sendo no final da safra em 2004 e no auge da safra em 2005. Nos dois anos, havia comunicações de queima aprovadas para a Usina Agrest ou para outros plantadores de cana no município de Espírito Santo do Turvo.

Observou-se que, nos dias 9 de novembro de 2004 e 11 a 13 de julho de 2005, quando havia comunicação de queima para área mais próxima da mancha urbana, os níveis tiveram um aumento significativo, sobretudo no período do início da noite, das $19 \mathrm{~h}$ às $20 \mathrm{~h}$ em 2005, e nos dois períodos em 2004. Mesmo assim, os níveis ainda foram inferiores ao padrão de qualidade para aqueles poluentes medidos. Entretanto, na primeira campanha, em 2004, havia chovido, e na segunda, em 2005, havia ventos mais fortes, apesar do tempo bom e da ausência total de chuvas. Tais elementos podem ter facilitado maior dispersão de poluentes e evitado concentrações maiores.

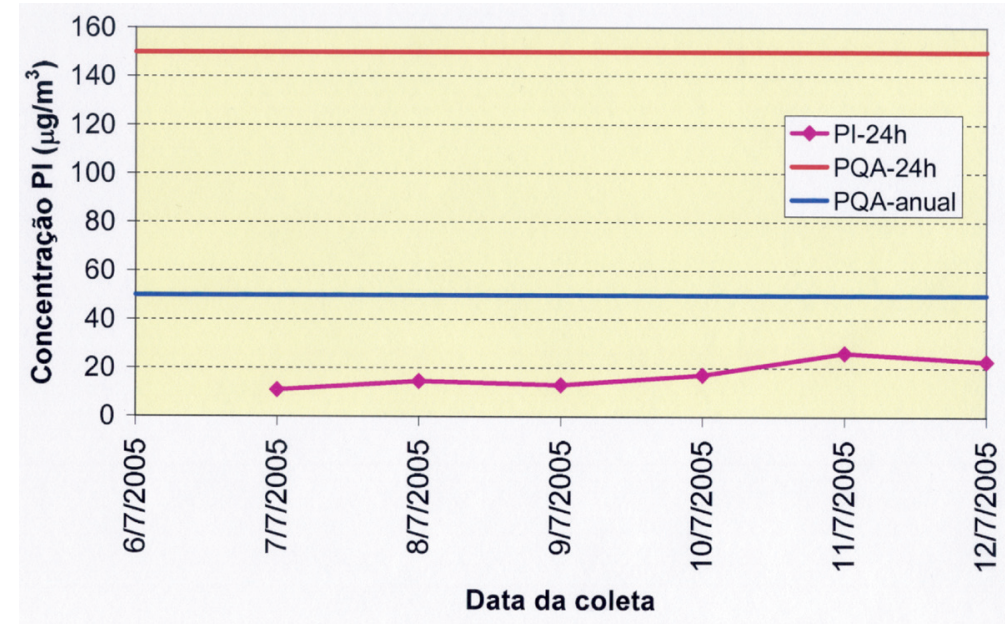

Figura 4 - Concentrações de Partículas Inaláveis (PI), no período de 6 a 13 de julho de 2005, e padrões de qualidade do ar diário e anual.

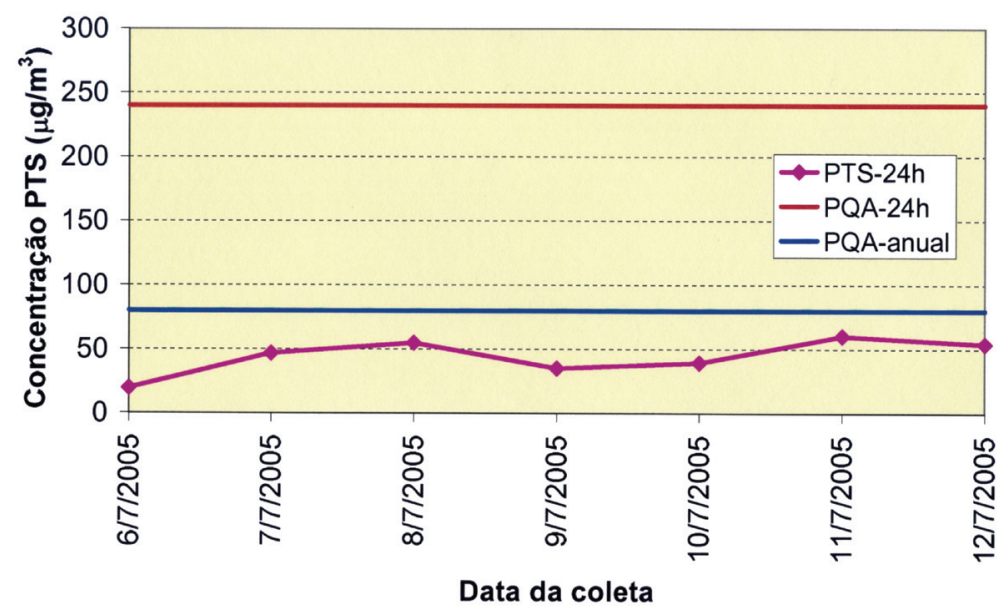

Figura 5 - Concentrações de Particulado Total, no período de 6 a 12 de julho de 2005, e padrões de qualidade do ar diário e anual, em área urbana de Espírito Santo do Turvo. 


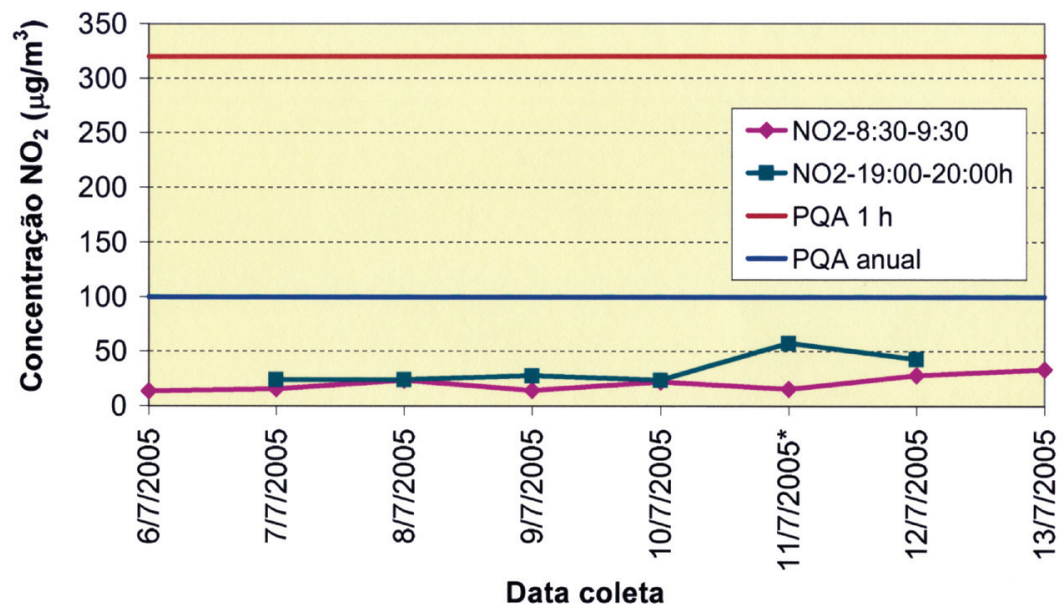

Figura 6 - Concentrações de dióxido de nitrogênio, no período de 6 a 13 de julho de 2005, e padrões de qualidade do ar para uma hora e anual, em área urbana de Espírito Santo do Turvo.

* Dia com queima de cana mais próxima da área urbana no final do dia.

\section{Morbidade referida pelos estudantes e comparação com dados de Juquitiba, na Região Metropolitana de São Paulo}

Dos 143 alunos que responderam ao questionário, $52 \%$ eram do sexo masculino e $47,6 \%$ do sexo feminino; $50,3 \%$ se declararam de cor branca; $40,6 \%$, de cor parda; $7,7 \%$, negros; e 1,4\%, amarelos. A data de nascimento dos entrevistados ia de janeiro de 1990 a dezembro de 1993. As idades variavam de 10 a 13 anos. A grande maioria dos entrevistados havia nascido na própria região: 42,8\% em Santa Cruz do Rio Pardo, município vizinho que possui maternidade, pois Espírito Santo do Turvo não possui hospital. Trinta crianças $(21,7 \%)$ nasceram em Ipaussu, outro município vizinho; 5,8\%, em Duartina; 4,3\%, em Espírito Santo do Turvo; 2,9\%, em Bauru; 2,2\%, em São Pedro do Turvo. Duas crianças tinham nascido no Nordeste do país (Alagoas e Pernambuco), duas no Paraná e duas em Mato Grosso do Sul. As restantes haviam nascido em municípios variados do interior do Estado de São Paulo.

Quanto ao local de moradia, três crianças haviam morado na Região Metropolitana de São Paulo; cinco, em Mato Grosso do Sul; três, no Paraná; uma, em Goiás; e uma, na Bahia; as restantes moraram em municípios do interior do Estado de São Paulo, sobretudo da própria região oeste. Sessenta e um por cento das crianças moravam no mesmo endereço havia cinco anos ou mais. Considerouse então que o local anterior de moradia teria um efeito desprezível no total das crianças no que diz respeito à exposição à poluição atmosférica.

Um dos indicadores sociais utilizados foi o número de pessoas dormindo no quarto: $28,7 \%$ das crianças dormiam sozinhas no quarto; $32,9 \%$ dormiam com mais uma pessoa; $23,8 \%$ dormiam com mais duas pessoas; e $14,7 \%$ dormiam com 
três ou mais pessoas no cômodo. Dentre as que dormiam com mais pessoas no quarto, 14,4\% delas tinham acompanhante que fumava; $71,6 \%$ dormiam sozinhas na cama; mas $15,5 \%$ dormiam com mais uma pessoa na cama; $6 \%$, com mais duas; e 6\%, com mais três pessoas na cama. As casas em que essas crianças moravam, em sua grande maioria $(85,4 \%)$, tinham de quatro a seis cômodos, incluindo a cozinha e excluindo o banheiro. Por sua vez, em $85,8 \%$ das casas moravam de quatro a sete pessoas. As condições de moradia dessas crianças, no geral, eram bastante simples, algumas precárias, por conta da aglomeração. Visita aos domicílios indicou que a grande maioria era coberta por telha vã, sem forro.

Em 99,3\% das casas onde moravam essas crianças, gás de botijão era o combustível usado para cozinhar. Só uma das casas usava fogão a lenha. A queima de biomassa no interior do domicílio, para cozimento dos alimentos, não constituía, assim, um fator de risco à saúde dessas crianças. Apenas $14,7 \%$ das casas não abrigavam animais de estimação. Em $31 \%$ das casas havia cachorros; em 4,9\%, gatos; em 17,5\%, gatos e cachorros; em 16\%, cachorros e pássaros; em 11,9\%, cachorros, pássaros e gatos.

Pela análise dos dados levantados na pesquisa de campo, verificou-se que, na cidade de Espírito Santo do Turvo, os níveis dos poluentes amostrados $\left(\mathrm{NO}_{2}, \mathrm{PTS}\right.$ e PI) em alguns dias nos anos de 2004 e 2005, durante a safra de cana-de-açúcar, em períodos em que havia comunicações de queima, apresentaram-se abaixo dos padrões recomendados pela legislação brasileira.

A prevalência de sintomas de doenças respiratórias em porcentagem de crianças de 11 a 13 anos, não obstante, foi alta. Comparando-se os dados obtidos em Espírito Santo do Turvo àqueles obtidos anteriormente em Juquitiba, verificou-se que, em 22 dos 28 sintomas de doenças ou doenças levantados por meio do questionário, os dados eram mais altos do que em Juquitiba, situada em área de proteção aos mananciais na Região Metropolitana de São Paulo. Só em seis sintomas, a prevalência foi proporcionalmente maior em Juquitiba. No entanto, porcentualmente, a diferença para menos em Espírito Santo do Turvo foi pequena nesses casos: doença no peito com mais catarro, hospitalização antes dos 2 anos de idade, pneumonia, cirurgia de amídalas ou adenoides e medicação para asma.

Tentou-se neutralizar influência de fatores socioeconômicos como fator de confusão nos resultados da pesquisa, selecionando-se alunos de escola pública estadual. No entanto, como não há escolas privadas nos dois municípios, supôs-se que a população analisada fosse relativamente homogênea. Considerou-se outro indicador socioeconômico: a escolaridade dos pais. Centrando a análise dos dois extremos, porcentagem de analfabetos e porcentagem de pais que cursaram a universidade, verificou-se que os níveis de analfabetismo entre os pais eram bem mais baixos em Espírito Santo do Turvo do que em Juquitiba. Não havia, contudo, pais que tinham cursado universidade em Espírito Santo do Turvo, e havia uma porcentagem pequena de pais com nível universitário em Juquitiba. Como a literatura aponta baixos níveis de escolaridade, sobretudo das mães, como fator de 
adoecimento em crianças, e, em Espírito Santo do Turvo, havia nível baixíssimo de pais $(1 \%)$ e mães $(1,6 \%)$ analfabetos, considerou-se que a baixa escolaridade não poderia ser responsabilizada pela significativa diferença entre a prevalência de sintomas para mais em Espírito Santo do Turvo.

Tabela 3 - Prevalência de sintomas e doenças em crianças de Espírito Santo do Turvo e de Juquitiba

\begin{tabular}{|c|c|c|c|c|}
\hline Sintoma /doença & $\begin{array}{l}\text { E. S. Turvo } \\
\text { N } 143\end{array}$ & $\%$ & $\begin{array}{l}\text { Juquitiba } \\
\text { N } 109\end{array}$ & $\%$ \\
\hline Tosse sem resfriado & 56 & 39,2 & 33 & 30,2 \\
\hline Tosse na maior parte dos dias & 20 & 18,3 & 9 & 8,2 \\
\hline Catarro sem resfriado & 31 & 21,8 & 18 & 16,5 \\
\hline Catarro na maior parte dos dias & 19 & 25,3 & 7 & 6,4 \\
\hline Peito congestionado + 1 semana/ano & 38 & 27,0 & 21 & 19,2 \\
\hline Chiado sem resfriado & 38 & 26,6 & 16 & 14,7 \\
\hline Chiado na maior parte dos dias & 34 & 23,9 & 17 & 15,5 \\
\hline Chiado com falta de ar & 39 & 27,5 & 21 & 19,2 \\
\hline Dois ou mais episódios de chiado & 26 & 18,2 & 13 & 11,9 \\
\hline $\begin{array}{l}\text { Necessitou tomar remédios para } \\
\text { chiado }\end{array}$ & 20 & 13,9 & 12 & 11,0 \\
\hline Respiração anormal nos intervalos & 22 & 15,4 & 12 & 11,0 \\
\hline Chiado após exercícios & 48 & 33,6 & 22 & 20,2 \\
\hline \multicolumn{5}{|l|}{ Doença no peito } \\
\hline Sem atividade por três dias & 17 & 12 & 7 & 6,4 \\
\hline Com mais catarro & 6 & 4,2 & 5 & 4,5 \\
\hline $\begin{array}{l}\text { Hospitalizado antes de } 2 \text { anos de } \\
\text { idade }\end{array}$ & 33 & 23,0 & 27 & 24,7 \\
\hline \multicolumn{5}{|l|}{ Outras doenças } \\
\hline Sarampo & 22 & 15,4 & 0 & 0 \\
\hline Sinusite & 27 & 18,9 & 6 & 5,5 \\
\hline Bronquite & 38 & 26,6 & 21 & 19,2 \\
\hline Pneumonia & 18 & 12,6 & 14 & 18,2 \\
\hline Dor de ouvidos & 90 & 62,9 & 63 & 57,7 \\
\hline \multicolumn{5}{|l|}{ Frequentes dores de ouvido } \\
\hline Entre $0-2$ anos & 10 & 7,2 & 5 & 4,5 \\
\hline Entre $2-5$ anos & 12 & 8,6 & 12 & 11,0 \\
\hline Com mais de 5 anos & 46 & 32,6 & 23 & 21,1 \\
\hline Tubos para drenar ouvido & 6 & 4,2 & 1 & 0,9 \\
\hline Cirurgia de amídalas ou adenoides & 2 & 1,4 & 2 & 1,8 \\
\hline Asma diagnosticada por médico & 3 & 2,1 & 2 & 1,8 \\
\hline Toma remédios para asma & 2 & 1,3 & 2 & 1,8 \\
\hline Alergia & 56 & 40,0 & 34 & 31,2 \\
\hline
\end{tabular}

Fonte dos dados de Juquitiba: Ribeiro \& Cardoso (2003). 
Outro importante fator de confusão em estudos de efeitos da poluição do ar na saúde de crianças é o hábito de fumar dos pais. Nesse caso, a prevalência encontrada em Espírito Santo do Turvo para hábito de fumar dos pais foi ligeiramente mais alta; para hábito de fumar das mães, foi semelhante nos dois municípios.

Os sintomas de doenças e doenças respiratórios encontrados estão apresentados na Tabela 3 .

Foi realizado o Student test para verificar a significância estatística das diferenças encontradas. No total de sintomas e doenças respiratórias, a diferença para mais em Espírito Santo do Turvo foi significante $(\mathrm{P}=0,04)$. Nos sintomas tosse sem resfriado e na maior parte dos dias, a diferença também foi significante $(\mathrm{P}=$ $0,01)$. Os sintomas peito congestionado mais de uma semana por ano, chiado sem resfriado, na maior parte dos dias, em mais de um episódio, tendo necessitado medicamentos, após exercícios e com respiração anormal nos intervalos, foram os que apresentaram maior significância estatística para mais em Espírito Santo do Turvo $(\mathrm{P}=0,008)$. Os outros sintomas com maior prevalência em Espírito Santo do Turvo, não apresentaram significância estatística.

\section{Conclusões}

A pesquisa realizada indicou que, no município de Espírito Santo do Turvo, os níveis dos poluentes amostrados $\left(\mathrm{NO}_{2}\right.$, PTS e PI), durante a safra de cana-deaçúcar, apresentaram-se abaixo dos padrões recomendados pela legislação brasileira. Não obstante, a prevalência de sintomas de doenças respiratórias em porcentagem de crianças de 11 a 13 anos foi mais alta em 22 dos 28 sintomas de doenças ou doenças levantados por meio do questionário. Como não foram encontrados outros fatores que pudessem explicar essa alta prevalência, há indicações de que a poluição advinda dos processos da agroindústria sucroalcooleira, em uso no município de Espírito Santo do Turvo, constitua num fator de risco à saúde respiratória das crianças, mesmo quando abaixo dos padrões de qualidade do ar. Há necessidade de desenvolvimento de mais estudos para avaliar esses efeitos, sobretudo neste momento de grande expansão das lavouras canavieiras no país.

\section{Agradecimentos}

Às escolas de Espírito Santo do Turvo pela autorização de realização da pesquisa.

Ao CNPq pelo financiamento da pesquisa com bolsa produtividade.

\section{Referências}

ABNT: NBR 13412. Material Particulado em Suspensão na Atmosfera - Determinação da concentração de Partículas inaláveis pelo Amostrador de Grande Volume acoplado a um Separador Inercial de Partículas. Jun. 1995.

ABNT: NBR 9547. Material particulado em suspensão no ar ambiente - Determinação da concentração total pelo método do Amostrador de Grande Volume. Fev. 1993. 
ARBEX, M. A. et al. Assessment of the effects of sugar cane plantation burning on daily counts of inhalation therapy. J. Air Waste Management Assoc., v.50, n.10, p.1745-9, 2000.

BERTOLANI, F. C. et al. Os solos e suas potencialidades. In: KRASILSCHIK, M. et al. Pesquisa ambiental: relato de um processo participativo de educação e mudança. São Paulo: Edusp, 2006.

BOOPATHY, R. et al. Sugar cane (Saccharum officinarum L) burning and asthma in Southeast Louisiana, USA. Bull Envir Contam Toxicol., v.68, n.2, p.173-9, 2002.

BRAUNBECK, O. A.; MAGALHÃES, P. S. G. Colheita sustentável, com aproveitamento integral da cana. Visão Agrícola, Piracicaba, v.1, n.1, p.72-78, 2004.

CANÇADO, J. E. D. A poluição atmosférica e sua relação com a saúde humana na região canavieira de Piracicaba - SP. São Paulo, 2003. Tese (Doutorado) - Faculdade de Medicina, Universidade de São Paulo.

DONZELI , P. L. et al. Diagnóstico do meio físico dos municípios com vistas à sustentabilidade da agropecuária. In: KRASILSCHIK, M. et al. Pesquisa ambiental: relato de um processo participativo de educação e mudança. São Paulo: Edusp, 2006.

FERRIS, B. G. Epidemiology standardization project. American Review of Respiratory disease, v.118, n.6, 1978.

IBGE. Instituto Brasileiro de Geografia e Estatística. Censo Demográfico 2000. Disponível em: <http://www.ibge.gov.br/ibge/estatistica/populacao/censo2000/sinopse>.

LODGE JUNIOR, J. P. Methods of air sampling and analysis. 3.ed. New York; Chelsea: Lewis Publishers, 1988. 763p.

LOPES, F. S.; RIBEIRO, H. Mapeamento de internações hospitalares por problemas respiratórios e possíveis associações à exposição humana aos produtos da queima da palha de cana-de-açúcar no estado de São Paulo. Rev. Bras. Epidemiologia, v.9, n.2, p.215-25, 2006.

O ESTADO DE S. PAULO. Safra de cana é recorde, mas abaixo do previsto; e No começo do ano carro fica mais caro. São Paulo, 5 jan. 2006. Economia, p.B3.

. O futuro do álcool. São Paulo, 25 fev. 2007. p.A3.

RIBEIRO, H.; CARDOSO, M. R. A. Air pollution and Health in São Paulo (19861998). Social Science and Medicine, v.57, p.2013-22, 2003.

RIBEIRO, H.; GÜNTHER, W. M. R. Grupos comunitários e instituições como atores e educação ambiental como instrumento do desenvolvimento socioambiental sustentado. In: KRASILSCHIK, M. et al. Pesquisa ambiental: relato de um processo participativo de educação e mudança. São Paulo: Edusp, 2006.

SILVA, C. Para as montadoras, vantagem do flex permanece. O Estado de S. Paulo, São Paulo, 5 jan. 2006. Economia, p.B3.

TORRES, R. B. Biodiversidade e remanescentes de vegetação nativa em Espírito Santo do Turvo e Vera Cruz. In: KRASILSCHIK, M. et al. Pesquisa ambiental: relato de um processo participativo de educação e mudança. São Paulo: Edusp, 2006.

WEEKES, D. Harvest management. In: JANES, G. Sugarcane. Oxford: Blackwell Publishing, 2004. 
WHO - World Health Organization. Selected Methods of Measuring Air Pollutants. Geneva, Switzerland, 1976

RESUMO - Pesquisa em Espírito Santo do Turvo (SP) analisou poluição atmosférica causada por queima de cana-de-açúcar e saúde respiratória de crianças. Realizaram-se medições de PM10, PTS e $\mathrm{NO}_{2}$, durante safra, em 2004 e 2005, em pátio de escola, e aplicouse questionário para avaliar morbidade respiratória referida dos alunos. No município, há cultivo de cana, queimada no pré-corte e usina próxima à área urbana. Resultados dos questionários foram comparados àqueles obtidos em Juquitiba (SP) previamente. As medições de poluentes, realizadas em dias em que havia queima de cana, estiveram abaixo dos padrões de qualidade do ar. Entretanto, foram indicadas altas prevalências de sintomas e doenças respiratórias.

PALAVRAS-CHAVE: Queimadas, Cana-de-açúcar, Morbidade, Doenças respiratórias, Crianças.

ABSTRACT - Research undertaken in Espírito Santo do Turvo (SP), analyzed data on air pollution caused by sugarcane burning and respiratory health of children. Measurements of PMI0, TSP, and $\mathrm{NO}_{2}$ were done during harvest period, in 2004 and 2005, at a public school patio and questionnaires to evaluate respiratory symptoms were applied to the school children. The municipality has predominantly sugarcane plantations and an alcohol processing plant close to urban area. Results of questionnaires were compared to those obtained in Juquitiba (SP), previously. Air pollution levels even during burning season were always bellow Brazilian standards. However, results indicated high prevalence of symptoms and of respiratory diseases.

KEYWORDS: Biomass fire, Sugarcane, Morbidity, Respiratory diseases, Children.

Helena Ribeiro é geógrafa, doutora em Geografia Física, bolsista CNPq Produtividade em Pesquisa 1C, professora titular do Departamento de Saúde Ambiental e vice-diretora da Faculdade de Saúde Pública da Universidade de São Paulo. @ - lena@usp.br

Célia Pesquero é doutora em Química e química do Laboratório de Qualidade do Ar da Faculdade de Saúde Pública da Universidade de São Paulo.

@ - celiapes@usp.br

Texto recebido em $1^{\circ}$.2.2008 e aceito em 31.7.2008. 